\title{
Analysis of Post-Consumer Solid Textile Waste Management among Households in Oyo State of Nigeria
}

\author{
K. O. Ajila \\ Department of Family, Nutrition and Consumer Sciences, Faculty of Agriculture, Obafemi Awolowo University, Ile-Ife, Nigeria \\ Email: olaoluajila@gmail.com
}

How to cite this paper: Ajila, K.O. (2019) Analysis of Post-Consumer Solid Textile Waste Management among Households in Oyo State of Nigeria. Journal of Environmental Protection, 10, 1419-1435. https://doi.org/10.4236/jep.2019.1011084

Received: August 8, 2019

Accepted: November 1, 2019

Published: November 4, 2019

Copyright ( 2019 by author(s) and Scientific Research Publishing Inc. This work is licensed under the Creative Commons Attribution International License (CC BY 4.0).

http://creativecommons.org/licenses/by/4.0/

\begin{abstract}
This research work viewed issues relating to post-consumers' solid textile waste management among households from a sociological perspective. The study was carried out in Oyo state of Nigeria. It specifically identified sources of post-consumer solid textiles waste, assessed waste management practices in the study area and, examined knowledge of respondent's on impact of post-consumers solid textile waste on the environment. Eight Local Government Areas were randomly selected from the state and, multistage random sampling procedure was applied in selecting 880 households for the study. Solid wastes generated by each of this household were collected twice a week. Sensitive and micro-census calibrated scale machine and weighing balance was employed in taking weight of the sorted textile wastes. Calibrated cylinder of radius $10 \mathrm{~cm}$ and height $40 \mathrm{~cm}$ was used in taking volume of the shredded waste. Mean value of post-consumer solid textile waste generated by individual was $0.11 \mathrm{~kg} \pm 0.08$, of volume $354 \mathrm{~cm}^{3}$ per day. Major identified waste disposal systems practiced by the respondents were open land surface dumping and open air burning. The respondents (100\%) strongly agreed that, wastes are often discards indiscriminately in the street by individuals. Level of awareness on danger created by poor waste disposal system among $78 \%$ of the respondents was low. None of the respondents have training on waste management neither is there any accessible training center in the studied area. Part of procedures to solve environmental problems can be by raising levels of awareness of individual household's, markets and institutional sectors on danger posed by poor handling of textile wastes to life and the environment, and be trained on waste management techniques. A functional and practically ideal waste management scheme should be established by the various organs of government mostly at the Local Government Area levels, and some investors could also be encouraged in instituting such schemes. Re-
\end{abstract}


search institutes in the country should develop appropriate technologies and trainings on waste management. Apart from salvaging the environment, such schemes will also provide job to cushion poverty mitigation in Nigeria.

\section{Keywords}

Post-Consumers, Household, Textile, Waste, Management

\section{Introduction}

Textile is a general term used for fiber, yarn and fabrics or any product made of these three materials. It is used for broad specification of purposes so much be that life is not likely to be sustained in its absence. Textiles are used in the production and processing of many items used in day to day living such as food, and manufacturing goods. No individual is independent of textile from cradle to earth, even the death and mad man in the street. Either synthetics or man-made, textile humanized the environment more than any other object [1]. Globally, textiles represent the second largest industrial sector that creates employment for people [2]. Apart from job provision, the industries feed several other manufacturing industries in producing materials for human and non-human consumptions. The industry is multiphase and has developed tremendously with discoveries of sophisticated technologies for its vast operations. Textile production passes through several mechanisms stages and each stage requires peculiar technologies with the use of large amounts of chemicals, heavy machines, water, and heat. Outside textile production mechanisms that generate a huge amount of waste (pre-textile waste), enormous quantities of waste are also generated with its use and discards (post-textile waste) [3]. Post-consumer solid textile wastes are generated from any solid textile articles that the owner no longer needs and decides to discard. In the context of the study, solid textile articles consist of solid materials used in food processes and packaging, clothing and fashion accessories, soft home furnishing materials such as paper, plastic, rubber, fabric, and leather products.

Vital sustainability issues facing Nigeria in the past three decades is the quantity of waste being generated, and sent to landfill every day at a great cost to the environment. [3] estimated the average waste generated by an individual per day in Nigeria as $0.69 \mathrm{~kg}$. [4] had earlier specified that 25 million tonnes of municipal solid wastes is generated annually in Nigeria and the density of these wastes ranged from $250 \mathrm{~kg} / \mathrm{m}^{3}$ to $370 \mathrm{~kg} / \mathrm{m}^{3}$. As in 2019 , the quantity of solid waste generates per annum assumed 32 million tons, out of which only $20 \%-30 \%$ is collected [5]. For instance, Oyo State where this study was conducted, is one of the largest States in Nigeria with an estimated population of six million people. The headquarter of the State (Ibadan) alone generates 0.51 kilogrammes of solid waste per day [4]. [6] specified that the quantity of waste generated in Oyo State shows a positive correlation with rate of urbanization and population growth 
in the area. However, textile represented a high volume of these wastes because of its dominant value in the society. Textiles products are indispensable to human psychosocial and emotional wellbeing, and as such men will continue to use the products. As individual economics standard increases, uses of textile among households also increases, and so, increase in waste generated. [7] signified that the rate of consumption of textile materials increases everyday relative to population growth. There were several sources of textile waste generation such as textile manufacturing industries, the customers in the industrial manufacturing sector that uses textile as raw materials, and end-users of the products from these industries such as companies, hospitals and hotels, schools and individuals, food and agricultural sector.

Farming both aquatic and terrestrial still remains the mainstay of this country. The results of recent research have indicated that the country is facing severe problems of land leaching and degradation, as well as air and water pollution [8]. Part of government efforts towards achieving eco-friendly system includes promulgation of laws and regulations to safeguard the environment. These regulations include the Federal Environmental Protection Agency [FEPA] Act of 1988 and, Federal Ministry of Environment of 1999. In which each state and local government in the country was mandated to create environmental protection agency within its jurisdiction. The government further instituted National Integrated Municipal Solid Waste Management Intervention Programme. Despite these efforts, gradient line of waste problems in the country rises yearly. For example, the Oyo State Solid Waste Management Authority (OYOWMA) that was established to regulate solid waste in the area was restricted to the headquarter and its fringes. Hence, the failure of government efforts in achieving adequate waste management services led to privatization of this sector. Private participation in waste management has not been successful in Nigeria because such companies are profit driven and they are not monitored or regulated by government. Recently, some State governments in Nigeria such as Lagos, Osun, Oyo, Ondo, Portharcourt, Edo among others established waste management system and integrate this into its youth employment schemes, by employing able bodied men and women, who are mandated to keep the environment clean. This job specification involves keeping the environment clean by clearing of weeds and, removal of waste from the main streets. Their efforts have however not made significant impact in the society. Again, some investors also established waste management industries dealing with recycling of post consumers' solid waste like plastics, metal and rubbers, but problem of pollution persist and unclear.

In the developed world apart from the hospital textile waste, most of the unused textile wastes were of reasonable to good quality that can be recovered and subsequently recycled. Clothing that is unlikely to be worn again is potentially functional as it may be shredded into fibre to be used in producing similar in nature to those manufactured from pre-consumer textile waste. Recycling of this nature is achieved with supportive technologies and hence generates job oppor- 
tunities. As at the time of this study, apart from higher level of joblessness in Nigeria, environmental problems is getting worst everyday with increase global warming, land degradation, water and air pollution. [9] indicated that the level of effectiveness of these various efforts towards solving environmental problems in Nigeria was low and their impact was not felt in most cities and towns, and that its citizens lack training on waste disposal. In 2019, the government adopted a new strategy in solving this grandiose problem by passing a bill to ban plastics bags. The plastic bag prohibition bill provides for an act to prohibit the use, manufacture and importation of plastic bags used for commercial and household packaging. This is to address harmful impacts of this material to oceans, rivers, lakes, forests, environments as well as human being and, also to relieve pressure on landfills and waste management and other related matters [10].

The study therefore, focused on issues relating to post-consumers' solid textile waste management and, it sociologically;

- identified sources of post-textiles waste, and physical composition of the waste generated,

- assessed various waste management systems practices in the study area and,

- examined knowledge of respondents on impact of post-consumer solid textile waste on the environment.

\section{Materials and Methods}

\subsection{Study Area}

The study was carried out in Oyo State of Nigeria. The State lies in the Southwestern region of the nation. It shared boundary in the south by Ogun State, in west by Republic of Benin, east by Osun State and in the north by Kwara State. The study area is highly urbanized with clusters of industries and, it consists of thirty three Local Government Areas (LGAs). According to Nigeria population census of 2006, the population of this State was about 5,591,589. Administratively, each of the LGAs is divided into "wards" based on the land mass and population density. Traditionally, people from this area are farmers, traders, and craftsmen. The high level of industrialization in the area does not change the State cultural mainstay.

\subsection{Sample Selection and Research Instruments}

Eight LGAs (number of wards) in the State viz as Akinyele (12), Ibadan-South-East (12), Ogbomosho-North (10), Saki-West (11), Orelope (10), Ibarapa-East (10), Afijio (10), and Oyo-East (10) were randomly selected for the study. Multistage sampling technique was applied in selecting 50 percent of the administrative wards from each selected LGAs totaling 44 wards. Cluster and simple random sampling procedure was applied in selecting 20 households from each ward making a total of 880 households for the study throughout the State. Household in the study comprises of groups of family that dwell in the same house. Data was collected within the period of March, 2019-June, 2019. Ques- 
tionnaires, personal interactive and observation, including Focus Group Discussion (FGDs) sessions were used in gathering primary data from the respondents on sources of post-consumer solid textile waste; waste management system practices and, knowledge on impact of textile waste on the environment. Again, laboratory analysis was applied to identify physical compositions, weight and volume of waste generated by respondents. Secondary data were collected from existing studies on fibre characteristics; impact of textile waste on the environment, and globally existing waste management system.

\subsection{Measurement Survey and Data Analysis}

Solid wastes generated by each of the households were collected twice a week. Wastes gathered were aired and dried in the sun for two days before subjected to manual sorting, where solid textile waste products were separated from non-textile waste. Solid textile wastes were further sorted into groups based on their visual components. Sensitive and micro -census calibrated scale machine and weighing balance was employed in taking weight of the sorted wastes and recorded as data bank The solid textile waste was later shredded into a small particle by a shredding machine. Calibrated cylinder of radius $10 \mathrm{~cm}$ and height $40 \mathrm{~cm}$ was used in taking volume of the shredded waste. Descriptive tools such weighted mean value, percentage and standard deviation was used in describing the collected data. Again the respondents were given statements of opinion about knowledge on impacts of textile waste on the environment in relation to the selected variables, and was based on five point Likert scale; Strongly Agreed $(\mathrm{SA}=5)$, Agreed $(\mathrm{A}=4)$, Undecided $(\mathrm{U}=3)$, Disagreed $(\mathrm{D}=2)$, and Strongly Disagreed $(\mathrm{SD}=1)$.

\section{Results and Discussions}

\subsection{Sources of Post Consumers Textile Waste and, Composition of the Waste Generated}

In-depth analysis showed that every individual (100\%) household in the studied area feed or drinks from outside their home daily in the form of industrially manufactured snacks or real meal. Fabrics of composite fibre were used for packages in form of disposable nylon and plastics as indicated in Figure 1, including cartons, papers among others as indicated by all (100\%) the respondents. While 91\% (8001) of the studied households strongly preferred imported textile goods from developed nation because of durability of such goods, $73 \%$ (642) often opt for imported fairly used materials. This was attached to the fact that the cost prices of imported textile fairly used materials are relatively low compared to new ones. Nigeria has been suspected to be one of the greatest producers of waste, and one of the causative factors was found to be as a result of high importation of fairly used materials, mainly from developed countries [11]. These goods permeate every family to every organization without adequate system of disposing and management after used. Improved style of living through 


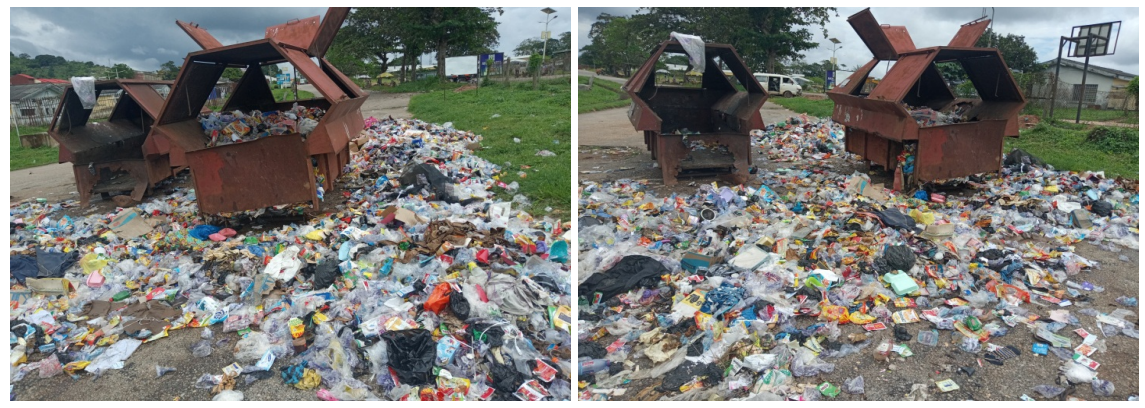

Figure 1. Textile wastes from disposable water sachets and plastics bottles dumped at the service unit of an eatery. Source: Field of survey, 2019.

globalization, coupled with poor economics faced by individual household in Nigeria are major causes of these odious importations. [12] identified high rate of importation of fairly used materials into Nigeria. According to the ratio of fairly used materials to a new one among household in Nigeria was 9:1, this assessment involves textiles and every others household goods. He further identified that the ratio of fairly used cars to new one was 255:1 among Nigerian. The end use of these properties poses danger to the environment and the users because most textile processing involved used of heavy metal ions [13].

In-depth analysis identified mean value of solid textile waste generated by individual as $0.11 \mathrm{~kg} \pm 0.08$ of volume $354 \mathrm{~cm}^{3}$ per day. The study revealed that textile has the highest volume of the total waste generated per day but not the highest weight. It was also identified that women generated more waste than men mostly in the area of clothing's (apparels, cosmetics, and baby toiletries). Average wardrobe size of the respondents was 26. This includes clothes and every other fashion items consumed by an individual such as garments, bags, shoes, among others. The mean value of other textile items consumed/owned by the selected household was 41 . This includes plastics and rubbers (bowls, plates, cups etc.) and soft furnishings materials (beds and beddings, curtains, rugs, carpet and others). It was also identified that textile care (cleaning and storage) procedure and additives used releases toxic wastes into the environment. The average services outlets per square kilometer in the studied area were 3 . This involved food services centers (such as farm products, industrially manufactured cooked and uncooked food), and apparel/clothing industries (viz as cosmetics, leather work, fashion designer, textile care and merchandiser), and about $83 \%$ packaging materials used from these service outlets were textile. It was isolated that, highest percent $(60 \%)$ of the solid textile waste generated by individual per day was originated from food and drinks packages. This is in accordance with [14] finding that, the highest proportion of municipal solid waste was generated from the kitchen. This was followed by apparel/clothing (36\%), while paper such as magazines, newspapers, notebooks and others was $4 \%$ of the waste generated by individual/day. The negative effects of all these wastes on the environment have not received adequate attention from individuals, governments, industries and the community. 
The lifecycle of textile are in the following order; production $\rightarrow$ use $\rightarrow$ disposal. Each of the stages has peculiar ways of generating waste of high intensive energy, generation of hazardous air emission, and degradation of the land [15]. The basic unit block in textiles is fibre (carboxylgroup). The polymers in these carboxyl groups differ from each other in types of chains length and attached additives. According to [16], natural fibres are more environmental friendly in contents than synthetic fibres. In his analysis of some selected synthetic fibres it was showed that; acetate is renewable, reusable and biodegradable but, it uses catalytic agents containing cobalt or manganese in it production: and that Polyester (PET) is non-renewable, non degradable, and involves use of carcinogenic chemicals such as benzene, toluene, arsenic, and heavy metals including antimony. An allergy-provoking dyes and carriers are added to its contents. Olefin (Polypropylene and Polyethylene) involves use of many carcinogenic chemicals such as lead based pigments. Additives such as anti-oxidants, Ultra-Violentstabilizers and flame retardants were added. It is non-degradable. Acrylic contents include carcinogenic chemicals such as vinyl acetate, acryl amide, N,N-dimethyl-formamid and acrylonitrile also known as vinyl cyanide [17]. It is non-degradable. [18] indicated that in the production of nylon, many carcinogenic chemicals such as benzene and hydrogen cyanide gas (nylon 6,6) are added as part of it components. Its manufacturing process creates nitrous oxide, a greenhouse gas, which is about 300 times more potent than carbon dioxide for producing global warming. In the production of Polyvinylchloride $(P V C)$ several carcinogenic chemicals such as phthalates are added. Phthalates are known as endocrine disrupters. Further again, PVC production generates dioxins, highly toxic substances that are linked with cancer. Dioxins are a global health threat because they persist in the environment and in mammals. It is non-degradable and harmful to the environment after disposal [19].

\subsection{Waste Management Systems Practice in the Study Area}

All (100\%) the respondents were aware of the following system of waste disposal; open land dumping, open air burning, burying, land filling, and decomposition. Major identified waste disposal system practiced among the studied households (100\%) were open land dumping Figure 2 and open air burning Figure 3. Analysis revealed that $34 \%$ of the respondents seldom practiced re-use system, incineration system $(8 \%)$ and, $2 \%$ practiced recycle and regenerating system respectively. This showed that households in the studied area are not aware of most available waste management's system. The common waste disposal practiced in the studied area was attached to the fact that most waste generated by the respondents lack second hand qualities. About $23 \%$ disposed waste through city council (government) issued rubbish bags via trunks and $77 \%$ were not. It was observed that waste collected by the government city council and its youth employment scheme are often dumped to formed a huge heaped on land surface in an undeveloped site in the city and along highway in the fringes Figure 4(a) and 
Figure 4(b), and seldom set on open air burning. Sixty percent of the respondents are also involved in dumping wastes along the highway within the community Figure 5. All the aforementioned system leads to poor sanitation and unaesthetic environment. The government charges its households and industries for the volume of waste they produce. The performance of waste disposal via government mechanism was rated poor because in most cases waste items are left uncollected for months as signified by all the respondents. All (100\%) strongly agreed that, wastes are often been discarded indiscriminately in the street by individual. It was also indicated that wastes generated are dumped at home yards (mostly at the services and living units of the yard) by individual and, $81 \%$ dumped waste in an abandoned/under-developed site within the community Figure 6 which later find their way to the street as litters. The generated waste littered the streets to developed un-healthy environment Figures 7 (a)-(c). It was specified that rain and wind often swept most of these wastes from street to gully and water core Figure 8. Fifty one percent dumped wastes on water trench Figure 9 and, once in a while all (100\%) of the respondents practices open air waste burning. None of the respondents have access to training on waste management system.

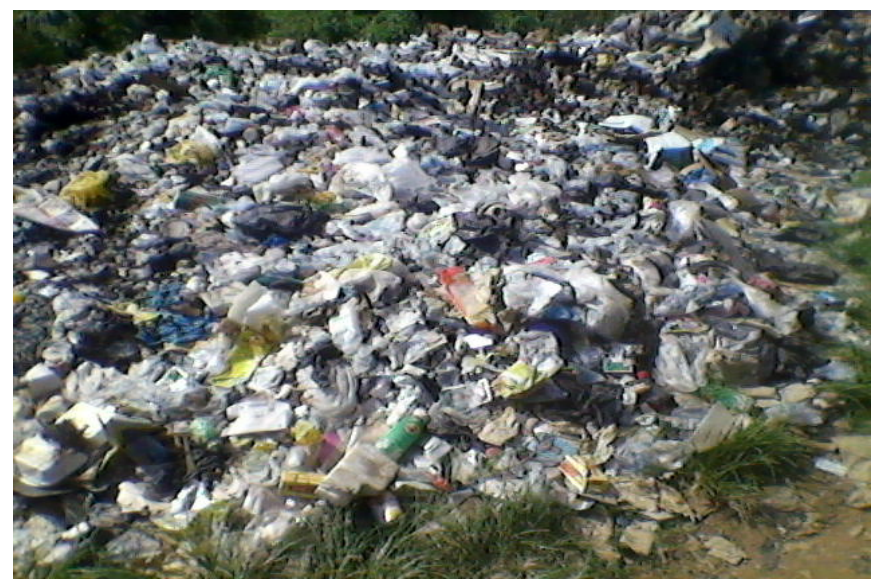

Figure 2. Solid wastes from different origin dumped on open land surface with high contents of solid textile materials. Source: Field of survey, 2019.

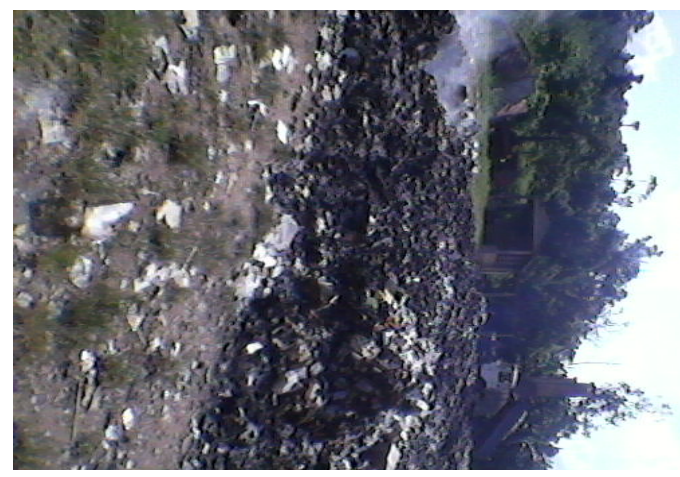

Figure 3. Open air burning wastes managements system on an undeveloped site within a residential area. Source: Field of survey, 2019. 


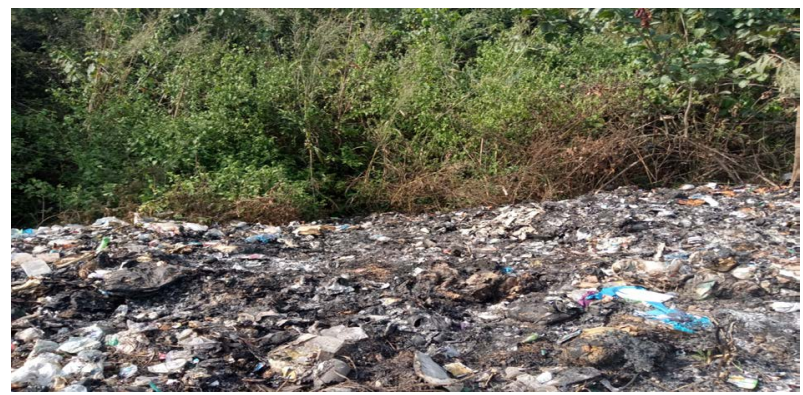

(a)

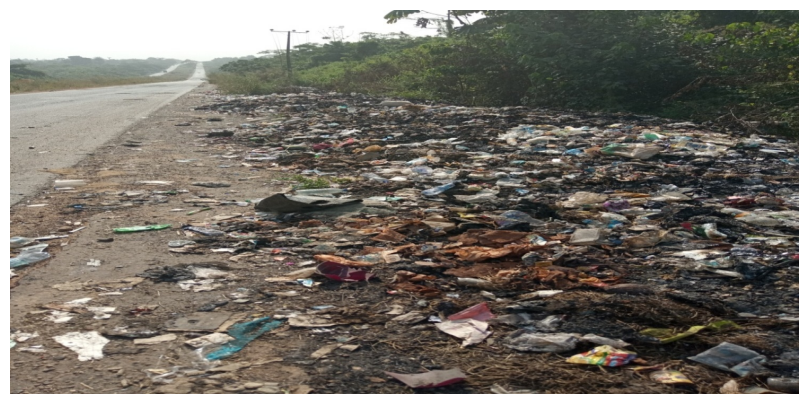

(b)

Figure 4. (a) Heap of wastes dumped in an undeveloped property within the community with high contents of solid textile materials; (b). Waste dumped along highway in the fringes with high contents of solid textile materials. Source: Field of survey, 2019.

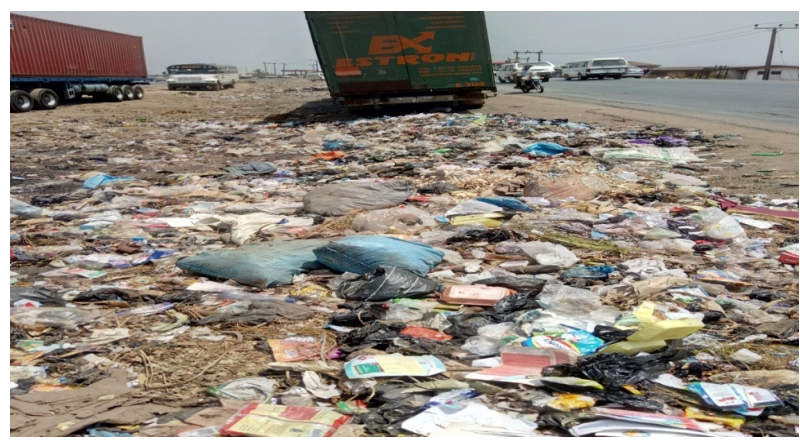

Figure 5. Waste dumped along highway in the metropolis with high contents of solid textile materials. Source: Field of survey, 2019.

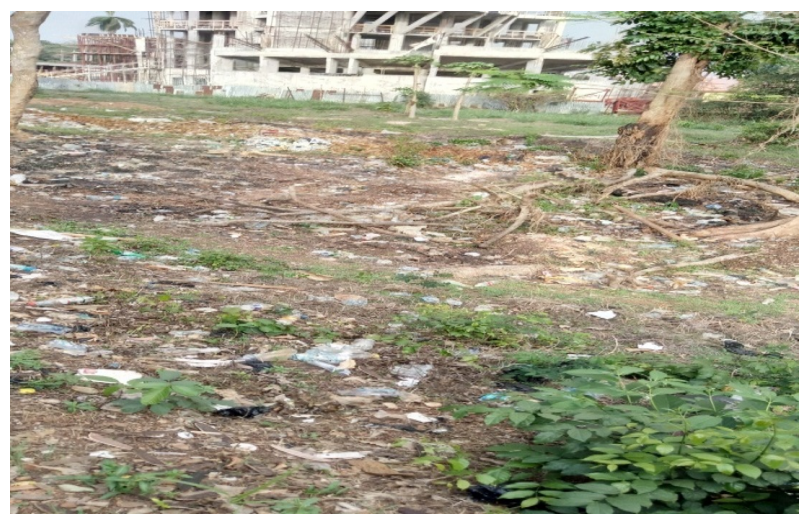

Figure 6. Wastes littering an under-developed property within the community with high contents of solid textile materials. Source: Field of survey, 2019. 


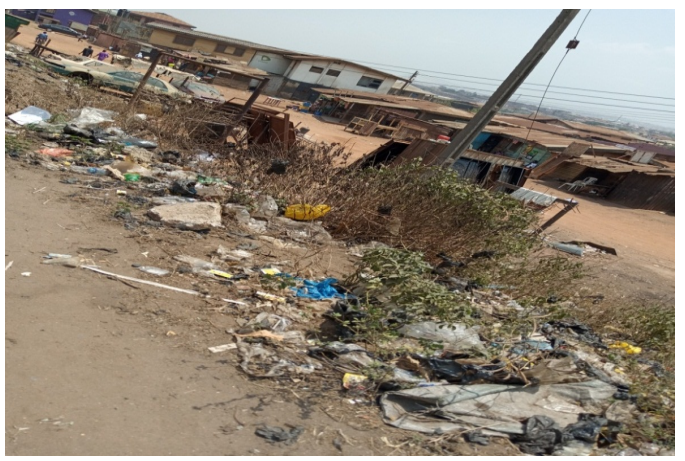

(a)

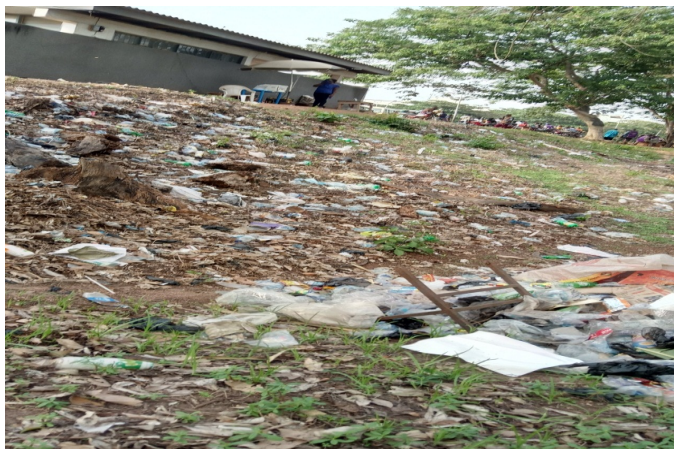

(b)

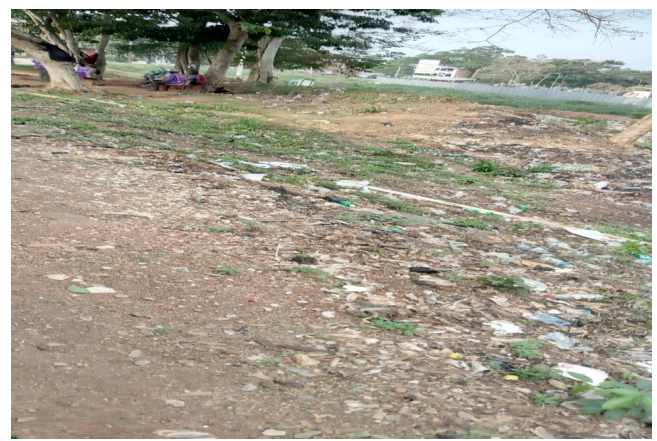

(a)

Figure 7. (a) Wastes dumped within residential areas with high contents of solid textile materials; (b) Wastes dumped within the business areas with high contents of solid textile materials. (c). Wastes scattered within industrial areas with high contents of solid textile materials. Source: Field of survey, 2019.

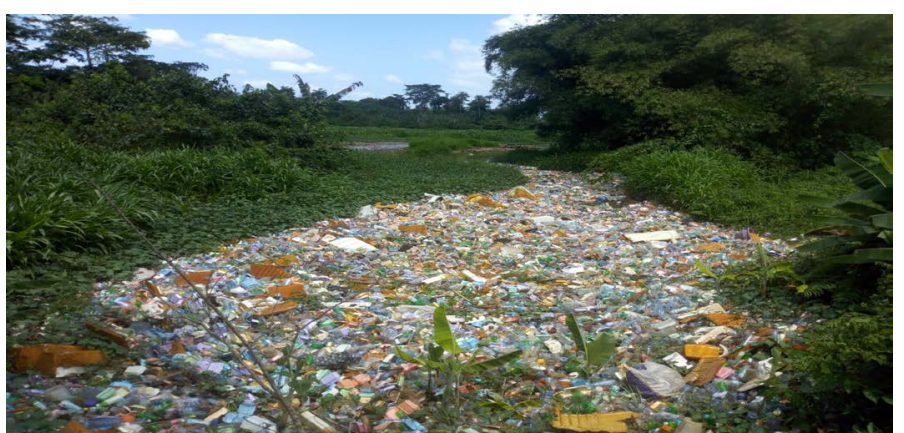

Figure 8. Wastes swept into water channel with high contents of solid textile materials. Source: Field of survey, 2019. 


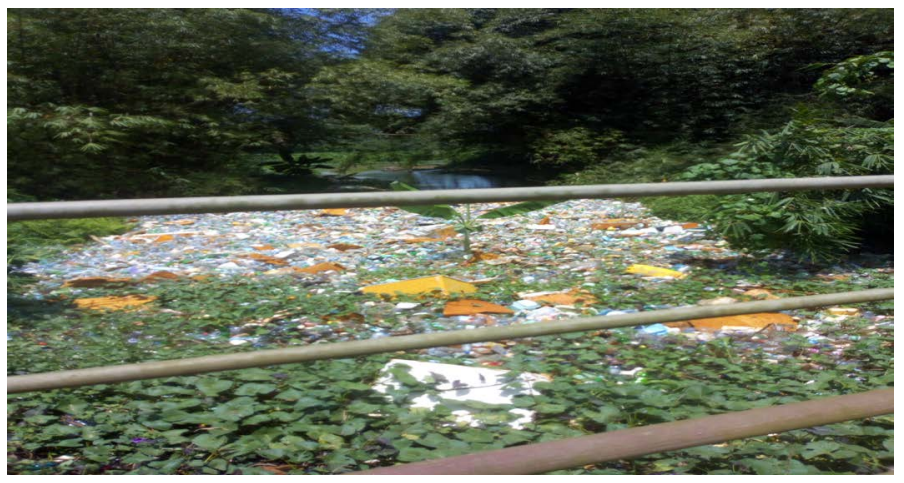

Figure 9. Wastes dumped into water channel with high contents of solid textile materials. Source: Field of survey, 2019.

Globally, there exist several management systems for textile waste viz and viz:

- Reuse reduction; this can effectively be achieved by internal -reuse of waste by given to others or reconstruct to something else that will be useable in the household. This study discovered that $80 \%$ waste generated by the respondents cannot be reused in its original form.

- Incineration; means burning of waste to generate heat energy. This study specified that majority (69\%) of the respondents are aware that textile goods can be used to generate heat but were not practicing it because the smolder produced in the process is very thick and dangerous. Also, 67\% of the respondents' indicated that most solid textile waste explodes in fire while, $43 \%$ identified that the fume produce causes eyes irritation, 39\% indicated that the ashes generated represent another toxic material in the environment. [18] specified that the chimney uses in incineration method do emit organic substances that pose danger to the environment such as dioxins, heavy metals, acidic gases and dust particles.

Appropriate technological waste management method refers to as recycling [16]. He identified recycling method as a key concept of modern waste management which means reprocessing of waste materials into new or reusable products and that ninety-nine percent of used textiles polymers are recyclable. [20] highlighted the major effective way of salvaging the environment from pollution as recycled and, indicated that the least expensive and least adverse effect on the environment is when a component can be recycled into its original product. The second best is when it can be used in another article. According to [21], recycling technologies are categorized as primary, secondary, and tertiary. Primary approaches involve recycling a product into its original form; secondary recycling involves melting and processing materials into a new product that has a lower level of physical, mechanical and chemical properties. Tertiary recycling involves conversion of wastes into basic chemicals or fuels. Detail analysis identified that textile waste recycling project was instituted in Nigeria in the early 90's but the project crashed prematurely within a few years. Reason has been that most industries that could absorb the recovery folded up. [7] indicated that uptill late 90 's, the country has about 450 registered textile and garment indus- 
tries that were functional, unfortunately before the mid 2000's, about $90 \%$ the industries folded up except the garment industries that managed to survive. As at the time of this study there were, but little evidence of newly organized recovery of textile waste for reprocessing industries in some major cities of Nigeria.

There are numbers of ways by which textile wastes can be turned into an asset with investment in appropriate and intellectual technologies. For example, all textile wastes can be repurposed or regenerated into saleable and usable products by intelligent collection, sorting, reengineering and reprocessing. Products made by regenerating textile waste include acoustic textiles used for soundproof blocks, insulation, roofing felt, bank stabilization, and as pollution control filters. Other patents include technology to turn leather scraps into book covers and auto seating and, utilizing wood waste to manufacture moldable tiles, trim and panels. Carpet underlay, furniture removal felt, weed suppression and water retention felts are just some of the examples of products produced by regenerating textile wastes. Other methods of regenerating fiber from fabrics are to breakdown fabric to fiber. The fiber could be re-engineered into:

- Re-granulation that connotes processing of waste from thermoplastic fibres to make free flowing granulates which can be used to produce fibres that could be melted to produce heavy viscous. This product is used as heavy-insulation layers or as a powdery binder agent to substitute phenolic resin when producing thermally bonded nonwovens and mats.

- Textile chips (TC) which mean converting nonwoven waste into textile chips. One may cut, mill or shred it. TC can be added as auxiliary material to produce textile concrete in building and road construction.

- Re-use of nonwoven waste typically involves conversion of textile fibre that has lost its intended values, into a new application with little or no alteration in the fibre generic. Example is the application of nonwoven waste in form of fibre-webs in road construction and other civil engineering works. The above claim is in accordance with [22]. Major identified re-use of nonwoven waste in the studied area, is the application of fibre waste in mattresses and pillow production.

Detailed analysis specified that, recycling industries were sited in few cities in Nigeria by individual investors with low level of performances. Major reason given by these investors for low performances includes poor funding and government policies mostly on high tax. It was revealed that supporting textile waste management technologies is sustainable for job creation towards national economic development. Regeneration verifiably reduces environmental impact of carbon emissions, energy use and toxic chemical up to $70 \%$ [23]. It was also identified that huge volumes of scrap metal recovered from end-of-life products in Nigeria are being regenerated and shipped to China and other rapidly industrializing countries by few foreign investors. Hence, it is possible to use technologies and innovations to transform materials and resources regarded as waste into marketable products that will be of benefit to the Nigeria economy and environment. A paradigm for the study of textiles wastes management is as showed 
in Figure 10. Globally, recycling of textile still represents the most laudable method of waste management, and can be broadly grouped into thermal, material and chemical sectors [24]. 1). Thermal recycling basically produces electrical energy from textile wastes. The processes involve recovering of heat energy from incineration of fibre waste, and finally convert heat generated into electrical energy. This could have informed the submission of [25] that thermal recycling does not mean recycling of resources. In the course of this study, it was identified that heat generated during waste recycling among the few available recycling industries and other firms that generates heat energy as by-products in Nigeria are let loose into the air with strong atmospheric congestion. 2). Material recycling recuperates polymers from textile wastes of fibers or plastics materials. This method often produces polymers of low quality and spinning stability, which is linked with the method is suitable to let impurities mix with recovered polymers. Material recycling is the major highlighted recycling system practices among waste management investors in the studied area. 3). Chemical recycling is when polymers of fiber wastes are broken down into monomers. Recovered monomers can be cleaned off impurities to attain exact quality of the original monomers. Indepth analysis revealed that, this method is highly expensive hence, not practiced.

\subsection{Knowledge on Impact of Textile Waste on the Environment}

Level of awareness on danger caused by poor waste disposal system among the respondents (78\%) was low. All (100\%) the respondents identified unaesthetic, unhygienic, stench environment as well as blocked drainages as major impact of poor waste management in the studied area. They were strongly agreed those post-textile waste products are major components of the wastes in most drainage channels. There was incessant blocked drainage in the studied area that often led to flooding during rainy seasons which had eventually claimed lives and properties. [26] identified that, most textile waste in landfill contributes to the formation of leachate as it decomposes, which has potential of contaminating groundwater. This might have been part of reasons of high level of groundwater contaminations in Nigeria as identified by [3]. Chemical Oxygen Demand (COD) and Biochemical Oxygen Demand (BOD) of several water sources in the nation have increased, and as such become inhabitable for aquatic plants and animals [27]. About $78 \%$ of the respondents agreed that post-consumer textile wastes can contaminate surface ground water, but $71 \%$ disagreed that post-consumer textile waste can contaminate underground water. Another product of decomposition in landfill is methane gas, which is a major cause of greenhouse gases and this contributes significantly to global warming. [28] suggested that, a major factor in the high rate of health deterioration in Nigeria was attached to high level of global warming. Sixty nine percent of the respondents were aware of high level of global warming in Nigeria, but $58 \%$ disagreed that global warming can be induced by poor post-consumer textile waste management. Again, 65\% disagreed that poor post-consumer textile waste management 


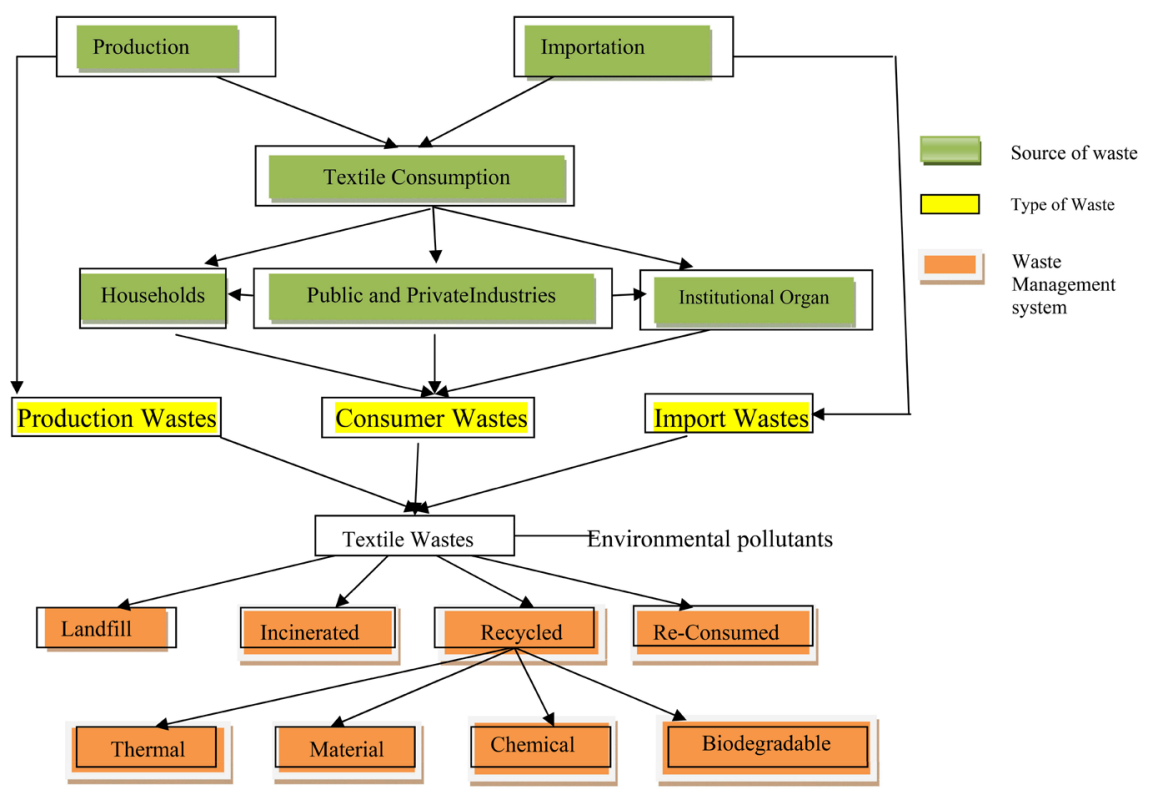

Figure 10. Paradigm for the study of textile waste management. $\rightarrow:$ Arrow indicating direction of influence. Source: Field of survey, 2019.

is a contributing factor in land degradation and, 35\% agreed. Sixty-two percent disagreed that poor textile waste management influence rate of health deterioration. [29] indicated that decomposition of organic fibers and yarn such as wool produces large amounts of ammonia as well as methane. However, ammonia is characterized as highly harmful and became more deadly in gaseous form to life and the general environment. Since major household waste management practiced in the study area are open landfill and open air burning therefore, there will be constant and high rate of ammonia gas release into the environment.

This study established that synthetics fibres are used in larger quantities among Nigeria households, and wastes generated with the use were often dumped to litter the environment without any proper disposal system. The wastes will eventually result in land degradation and greenhouse gas formation for global warming. Apart from the fact that synthetic fibers are cheap and easy to maintain as compared to natural fibre [1], it was identified that inability of natural fibre production to meet the ever growing population had led to the usage of synthetic fibre quantitatively. Among studied households it's hard to find a textile material made of 100\% natural fibre, even the indigenous fabrics. Most are either 50:50, or 75:25 synthetic to natural fibre. Howbeit, synthetics textile production involve used of more toxic chemicals, which are very hard to recycle [19]. These fibres prolong the adverse effects of both leachate and gas production due to the length of time it takes them to decay. Detailed analysis revealed that textile materials have no second hand value in Nigeria, coupled with the facts that, major methods of waste disposal are open land dumping and open air burning, hence there is continuous addition of waste to the environment. Burning of post-consumer textile waste, mostly the synthetics textiles emits high magnitude of organic substances such as dioxins, heavy metals, acidic gases and dust par- 
ticles [30]. These are potentially hazardous to both humans and the environment.

\section{Conclusions and Recommendations}

Major post-consumer textile waste disposal systems practiced in the studied area were open land dumping and open air burning. Level of awareness on danger caused by poor post-consumer textile waste disposal system among the respondents was low. There was no accessible waste management training center in the studied area and, individual household lacked knowledge on effective waste management system.

It is therefore, recommended that individual consumers, households, and the society in general can be educated on threats posed by poor handling of textile wastes to life and the environment. Professional training courses on waste management should be made accessible to meet the manpower need of the waste industry. Constant public enlightenment and training on proper wastes handling and economics potentials of waste management should be provided by the government and, such enlightenment could be managed by the extension agency, health, and other environmental crusaders. Again, every State and Local Governments in the nation should institute an appropriate and functional wastes management policy and control that will be community based. At the same time, an ideal waste management scheme should be inaugurated at the Local Government Area levels, and private investors could also be encouraged in instituting such schemes. Research institutes in the country should be supported to develop suitable technologies for the scheme. Involvement of the civic via some of the community based organizations is very vital towards the success of such training and scheme. Apart from the fact that this will salvage the environment, it will also create job opportunities for the unemployed sector mostly the youth.

\section{Conflicts of Interest}

The author declares no conflicts of interest regarding the publication of this paper.

\section{References}

[1] Ajila, K.O. (2011) An Evaluation of Textile Extension Services of Ondo State Agricultural Development Programme, Nigeria. PhD Thesis, Department of Agricultural Extension and Rural Sociology, Obafemi Awolowo University, Ile-Ife.

[2] Ibrahim, H.D. and Ogunwusi, A.A. (2017) Prospects for Kenaf Textile Production in Nigeria. Journal of Natural Sciences Research, 7, 22-28. http://www.iiste.org

[3] Adewumi, I.K. (2015) Engineering: The Environment. An Inaugural Lecture, Niger Delta University, Wilberforce Island.

[4] Abila, B. and Kantola, J. (2013) Municipal Solid Waste Management Problems in Nigeria: Evolving Knowledge Management Solution. World Academy of Science, Engineering and Technology. International Journal of Environmental and Ecological Engineering, 7, 303-308. 
[5] Bakare, W. (2019). http://www.bioenergyconsult.com/solid-waste-nigeria

[6] Lawal, B.S. (2017) Factors Influencing Oyo State Waste Management Scheme. M.Sc. Thesis, Institute of Ecology and Environmental Studies, Obafemi Awolowo University, Ile-Ife.

[7] Oyewale, L.O. (2018) Management Competence as Correlates of Staff Efficiency in Textile and Fashion Industries in Southwestern, Nigeria. B.Sc. Thesis, Department of Consumer Sciences, Obafemi Awolowo University, Ile-Ife.

[8] Adenekan, A.A. and Elujoba, O.O. (2010) Life Cycle Management of Municipal and Livestock Solid Wastes Using Biomethanation. B.Sc. Thesis, Department of Civil Engineering, Obafemi Awolowo University, Ile-Ife.

[9] Ogwueleka, T.C. (2009) Municipal Solid Waste Characteristics and Management in Nigeria, Iran. Journal of Environmental Health Science and Engineering, 6, 173-180.

[10] The Guardian (2019) Nigeria National House of Representative: Bill to Ban Plastic Bags. Nigeria Newspaper, 21st May 2019. https://m.guardian.ng

[11] Onakpohor, A. (2013) Analysis and Evaluation of Emissions from Tombia Road Municipal Wastes Dump Site in Tombia, Bayelsa State, Nigeria. M.Sc. Thesis, Institute of Ecology \& Environmental Studies, Obafemi Awolowo University, Ile-Ife.

[12] Dotton, E.O. (2016) Importation of Fairly Used Material as a Correlate to Sustainable Poverty Alleviation in Nigerian. Economic Review, 1, 148-154.

[13] Guner, M. and Yucel, O. (2005) Environmental Protection and Waste Management in Textile and Apparel Sector. Journal of Applied Sciences, 5, 1843-1849. https://doi.org/10.3923/jas.2005.1843.1849

[14] Yenice, M.K., Dogruparmark, S., Durmusoglu, E., Ozbay, B. and Orkumoz, H. (2011) Solid Waste Characterization of Kocaeli. Polish Journal of Environmental Studies, 20, 479-484.

[15] Sekorowei, M.C. (2013) Heavy Metals Concentration in Edible Foodstuffs and Water in Odimodi, Burutu Local Government Area, Delta State. BSc Thesis, Department of Civil Engineering, Niger Delta University, Wilberforce Island.

[16] Katkar, P.M. (2010). http://www.fibre2fashion.com

[17] Alagöz, A.Z. and Kocasoy, G. (2007) Improvement and Modification of the Routing System for the Health-Care Waste Collection and Transportation in Istanbul. Waste Management, 28, 146-158. https://doi.org/10.1016/j.wasman.2007.08.024

[18] Sohgo, et al. (2016) Environmental Pollution and Incineration Technology among Waste Management Industries in Nigeria. PhD Thesis, Faculty of Technology, University of Ibadan, Ibadan.

[19] Sambule, C.A. (2011) Impact of Textile and Clothing Industry on Environment: An Approach towards Eco-Friendly Textiles. Australia, 43-51.

[20] Cointreau, S.J., Gunnerson, C.G., Huls, J.M. and Seldman, N.N. (1984) Recycling from Municipal Refuse: A State of the Art Review and Annotated Bibliography. World Bank Technical Paper No. 30. The World Bank, Washington DC.

[21] Adewumi, I., Seimodei, T., Adekola, S. and Sapre-Obi, E. (2014) Developing a Town-Gown Electronic Wastes Recycling Process in Nigeria. Going Green Care Innovation. Paper 169, SAT Austrian Society for Systems Engineering and Automation, Vienna.

[22] Ajmeri, J.R. and Ajmeri, C.J. (2016) Advance in Technical Nonwovens Development: In Nonwoven Geotextiles, Elsevier. Woodhead Publishing Series in Textiles, 339-363. 
[23] Shih, L.H. and Chang, H.C. (2001) A Routing and Scheduling System for Infectious Waste Collection. Environmental Modeling and Assessment, 6, 261-275. https://doi.org/10.1023/A:1013342102025

[24] Odgwu, L.O. (2018) Waste Management Approach in Textile and Garment Making Industries in Lagos State of Nigeria. M.Sc. Thesis, Federal University of Technology, Akure.

[25] Hongu, T. and Glyn, O.P. (2001) New Fibers. Woodhead Publishing Limited, Cambridge.

[26] United States Environmental Protection Agency (1996) Best Management Practices for Pollution Prevention in Textile Industry. U.S. Environmental Protection Agency Document, No. EPA/625/R-96/004, 53-78.

[27] Adewumi, I., Oke, I.A. and Bamgboye, P.A. (2004b) Determination of the Deoxyegenation Rates of a Residential Institution's Wastewater. Journal of Applied Sciences, 5, 108-112. https://doi.org/10.3923/jas.2005.108.112

[28] Bello, A.S. (2015) Greenhouse Gas and Sustainable Health in Nigeria. Health and Materials, Bulletin, 7, 52-66.

[29] Shah, R. (2010) Examine the Role of Different Actors across the Textile Fashion Supply Chain to Understand the Issues Regarding Growth of Eco-Labeled Sustainable Textile Products. MSc. Dissertation, Faculty of Engineering and Physical Science, University of Manchester, London.

[30] Bako, S.S., Bako, W.S., Ishaya, K.S. and Pennap, G.R.I. (2007) Air Pollution and Climatic Change. Journal of Environmental Studies, 3, 68-74. 